\title{
A invisibilidade da branquitude na mídia e na música brasileira
}

\section{Ceiça Ferreira}

\section{Resenha}

SOVIK, Liv. Aqui ninguém é branco. Rio de Janeiro: Aeroplano, 2009.

\section{Conceição de Maria Ferreira Silva |}

ceicaferreira@gmail.com

Doutoranda no Programa de Pós-Graduação em Comunicação da Universidade de Brasília (UnB), na linha de pesquisa Imagem e Som.
0 livro "Aqui ninguém é branco" apresenta uma reflexão sobre a convivência inter-racial no Brasil, a partir do conceito de afeto, característica historicamente utilizada como metáfora da identidade nacional, e assim busca enxergar no país da mestiçagem, os silêncios e a invisibilidade da branquitude brasileira, presentes nos discursos midiáticos e na música popular.

Discutir o problema racial como problema do branco é certamente uma nova perspectiva para os estudos dessa área. Na primeira parte do livro, "Ensaios Teóricos", ancorada na obra de Guerreiro Ramos, a autora analisa a branquitude como um lugar de fala, privilegiado e inominado; não atrelado à genética, mas uma questão de imagem, um ideal estético.

Por isso, é no âmbito dos meios de comunicação, onde ora se valoriza 0 discurso da mestiçagem, ora não se menciona raça explicitamente, que esta obra busca entender a força da hegemonia branca. São utilizados como exemplos, a frase cômica "Nóis sofre mais nóis goza", de José Simão (colunista do Jornal Folha de São Paulo), e suas 
conotações de raça e gênero; e três versões do sequestro do ônibus 174, presentes nas revistas Veja, Istoé e Época, que são estudadas a partir da semiótica e do conceito de "Estranho familiar" de Freud, com o propósito de entender esse "Outro", que segundo os discursos veiculados nas reportagens, poderia ser "qualquer um de nós".

A importância simbólica da história do movimento dos direitos civis nos Estados Unidos, e principalmente, a forma de contála no Brasil é outra questão trabalhada nesta primeira parte do livro, que utiliza outro discurso midiático como exemplo, a matéria da revista Veja sobre os gêmeos, que foram classificados de forma diferente na seleção por cotas da Universidade de Brasília.

No uso descontextualizado do famoso discurso de Martin Luther King, na construção discursiva, que relaciona as cotas como uma importação de ideias norte-americanas; nos elogios à democracia racial brasileira; ou na visão reducionista da história norte-americana é que se expressa a posição deste veículo com relação às cotas.

Intitulada "Ensaios Musicais", a segunda parte do livro apresenta um estudo histórico da Bossa Nova. Além do seu prestígio e da qualidade estética, que ao contrário da figura caricata de Carmem Miranda, incluiu efetivamente a música brasileira na cultura cosmopolita internacional, também outras interpretações sobre esse gênero musical são indicadas na obra, como a negação de suas origens negras, ao associá-lo aos brancos de classe média.

Tal estratégia também se revela no silêncio da historiografia acerca da música que antecede à criação da Garota de Ipanema. Junto ao menosprezo pela música das rainhas do rádio, tão populares nos anos de 1950, se apagou também a história da cantora Angela Maria, que embora tenha sido superada pela bossa nova, ressurge atualmente, como símbolo de múltiplos deslocamentos de identidade de gênero e raça.

Um dos maiores sucessos da cantora, a música "Vida de bailarina", de Américo Seixas e Chocolate (Dorival Silva) também é analisada por Liv Sovik. Essa música e sua protagonista remetem a uma tensão, aos embates gerados pela mercantilização da vida afetiva, ao lugar social das mulheres subalternas (geralmente negras), que vivem no limiar entre 0 trabalho reconhecido e a prostituição.

A partir do corpo dessa bailarina, a autora questiona que corpo é esse no imaginário das relações raciais. Se em "Vida de Bailarina" assim como um lírio em lamaçal, pode-se ver esse corpo feminino como vítima, o mesmo não se pode dizer do corpo retratado na música "A carne", de Marcelo Yuka, Seu Jorge e Wilson Capellette. Esse corpo negro que, entendido como herança de uma história invisibilizada, coloca em questão a branquitude e luta por justiça.

Utilizando as técnicas do New Criticism, a autora analisa o cd e show "Noites do Norte", de 
Caetano Veloso, figura importante na cena cultural brasileira, que inspirado na obra do abolicionista Joaquim Nabuco reitera a escravidão como característica nacional.

Na busca por entender os sentidos políticos da obra, e diante das várias vozes ouvidas, Liv Sovik questiona o lugar de fala de Caetano em dueto com Joaquim Nabuco; discute a nostalgia presente no disco, alusão à convivência amena entre brancos e negros, o que confirma a complexidade das relações raciais brasileiras, característica já apontada por Joaquim Nabuco ao diagnosticar diferenças entre o racismo insidioso existente aqui e a situação norte-americana.

A última parte do livro examina posturas de brancos sobre raça em um ambiente onde 0 destaque é para a beleza negra, a música popular. Pensando a branquitude como valor, a autora questiona o sentido da identificação de Daniela Mercury com a cultura negra, e também seus posicionamentos, ora como branca, ora como negra, e principalmente, $o$ fato disso não suscitar estranhamento. Tal postura representa, segundo a autora, uma espécie de travestimento racial.

Também se discute a atuação de Gabriel 0 Pensador e a defesa da mestiçagem presente em suas letras. Para ele, a música é um instrumento de transformação, por meio da qual "dá um bom exemplo", educa o público, se faz mediador entre a cultura dominante e a periferia, e assim também revela 0 lugar de onde fala.

Com o subtítulo "Consolidação", o livro apresenta a vida e a carreira de Marcelo Yuka. Ao observar o quanto a temática da injustiça racial está presente em suas composições, como por exemplo, em "Todo camburão tem um pouco de navio negreiro", ou na já mencionada letra " $A$ carne", a autora aponta a postura desse letrista como uma crítica antirracista cidadã, uma nova possibilidade, dentro do campo discursivo do branco, que é o de se reconhecer como parte integrante de uma realidade predominante negra.

"Aqui ninguém é branco" traz à tona os silêncios, os discursos e valores que passam despercebidos, evidencia a hegemonia branca que se perpetua por meio da valorização da mestiçagem, até mesmo onde se destaca a cultura negra; e mais do que uma denúncia contra o racismo, a obra evidencia a hegemonia da branquitude nas estratégias mais sutis, que predominantemente ancoram-se no afeto. Logo, para se compreender as relações raciais, a autora aponta a necessidade de se atentar para complexidade da cultura brasileira, que agrega várias vozes, duplas consciências e múltiplos repertórios culturais. 


\section{Expediente}

A revista E-Compós é a publicação científica em formato eletrônico da Associação Nacional dos Programas de Pós-Graduação em Comunicação (Compós). Lançada em 2004, tem como principal finalidade difundir a produção acadêmica de pesquisadores da área de Comunicação, inseridos em instituições do Brasil e do exterior.
E-COMPÓS I www.e-compos.org.br I E-ISSN 1808-2599

Revista da Associação Nacional dos Programas

de Pós-Graduação em Comunicação.

E-compós, Brasilia, v.16, n.1, jan./abr. 2013

A identificação das edições, a partir de 2008,

passa a ser volume anual com três números.

\section{CONSELHO EDITORIAL}

Afonso Albuquerque, Universidade Federal Fluminense, Brasil Alberto Carlos Augusto Klein, Universidade Estadual de Londrina, Brasil Álvaro Larangeira, Universidade Tuiuti do Paraná, Brasil André Luiz Martins Lemos, Universidade Federal da Bahia, Brasil Ângela Freire Prysthon, Universidade Federal de Pernambuco, Brasil Angela Cristina Salgueiro Marques, Faculdade Cásper Líbero (São Paulo), Brasil Antonio Roberto Chiachiri Filho, Faculdade Cásper Líbero, Brasil Arthur Autran Franco de Sá Neto, Universidade Federal de São Carlos, Brasil Benjamim Picado, Universidade Federal Fluminense, Brasil César Geraldo Guimarães, Universidade Federal de Minas Gerais, Brasil Cristiane Freitas Gutfreind, Pontifícia Universidade Católica do Rio Grande do Sul, Brasil

Denilson Lopes, Universidade Federal do Rio de Janeiro, Brasil Eduardo Peñuela Cañizal, Universidade Paulista, Brasil

Eduardo Vicente, Universidade de São Paulo, Brasil Eneus Trindade, Universidade de São Paulo, Brasil Erick Felinto de Oliveira, Universidade do Estado do Rio de Janeiro, Brasil Florence Dravet, Universidade Católica de Brasília, Brasil Gelson Santana, Universidade Anhembi/Morumbi, Brasil Gislene da Silva, Universidade Federal de Santa Catarina, Brasil Guillermo Orozco Gómez, Universidad de Guadalajara Gustavo Daudt Fischer, Universidade do Vale do Rio dos Sinos, Brasil Hector Ospina, Universidad de Manizales, Colômbia Herom Vargas, Universidade Municipal de São Caetano do Sul, Brasil Inês Vitorino, Universidade Federal do Ceará, Brasil Jay David Bolter, Georgia Institute of Technology Jeder Silveira Janotti Junior, Universidade Federal de Pernambuco, Brasil John DH Downing, University of Texas at Austin, Estados Unidos José Afonso da Silva Junior, Universidade Federal de Pernambuco, Brasil José Carlos Rodrigues, Pontifícia Universidade Católica do Rio de Janeiro, Brasil José Luiz Aidar Prado, Pontifícia Universidade Católica de São Paulo, Brasil Kelly Cristina de Souza Prudêncio, Universidade Federal do Paraná, Brasil.
Laan Mendes Barros, Universidade Metodista de São Paulo, Brasil Lance Strate, Fordham University, USA, Estados Unidos Lorraine Leu, University of Bristol, Grã-Bretanha Lucia Leão, Pontifícia Universidade Católica de São Paulo, Brasil Malena Segura Contrera, Universidade Paulista, Brasil

Márcio de Vasconcellos Serelle, Pontifícia Universidade Católica de Minas Gerais, Brasil

Maria Aparecida Baccega, Universidade de São Paulo e Escola Superior de Propaganda e Marketing, Brasil

Maria Ataide Malcher, Universidade Federal do Pará, Brasil

Maria das Graças Pinto Coelho, Universidade Federal do Rio Grande do Norte, Brasil Maria Immacolata Vassallo de Lopes, Universidade de São Paulo, Brasil Maria Luiza Martins de Mendonça, Universidade Federal de Goiás, Brasil Mauro de Souza Ventura, Universidade Estadual Paulista, Brasil Mauro Pereira Porto, Tulane University, Estados Unidos Mirna Feitoza Pereira, Universidade Federal do Amazonas, Brasil Nilda Aparecida Jacks, Universidade Federal do Rio Grande do Sul, Brasil Osvando J. de Morais, Universidade de Sorocaba, Brasil Potiguara Mendes Silveira Jr, Universidade Federal de Juiz de Fora, Brasil Renato Cordeiro Gomes, Pontifícia Universidade Católica do Rio de Janeiro, Brasil Robert K Logan, University of Toronto, Canadá

Ronaldo George Helal, Universidade do Estado do Rio de Janeiro, Brasil Rose Melo Rocha, Escola Superior de Propaganda e Marketing, Brasil Rossana Reguillo, Instituto de Estudos Superiores do Ocidente, Mexico Rousiley Celi Moreira Maia, Universidade Federal de Minas Gerais, Brasil Sebastião Guilherme Albano da Costa, Universidade Federal do Rio Grande do Norte, Brasil

Simone Maria Andrade Pereira de Sá, Universidade Federal Fluminense, Brasil Tiago Quiroga Fausto Neto, Universidade de Brasília, Brasil Suzete Venturelli, Universidade de Brasília, Brasil Valerio Fuenzalida Fernández, Puc-Chile, Chile

Veneza Mayora Ronsini, Universidade Federal de Santa Maria, Brasi Vera Regina Veiga França, Universidade Federal de Minas Gerais, Brasil

\section{COMISSÃO EDITORIAL}

Adriana Braga I Pontifícia Universidade Católica do Rio de Janeiro, Brasil

Felipe Costa Trotta I Universidade Federal Fluminense, Brasil

CONSULTORES AD HOC

Bruno Campanella, Universidade Federal Fluminense, Brasil

Christa Berger, Universidade do Vale do Rio dos Sinos, Brasil

Edison Gastaldo, Universidade Federal Rural do Rio de Janeiro, Brasil

José Luiz Braga, Universidade do Vale do Rio dos Sinos, Brasil

\section{EDIÇÃO DE TEXTO E RESUMOS I Susane Barros}

SECRETÁRIA EXECUTIVA I Juliana Depiné

EDITORACã̃ ELETRÔNICA I Roka Estúdio
COMPóS I www.compos.org.br

Associação Nacional dos Programas de Pós-Graduação em Comunicação

Presidente

Julio Pinto

Pontifícia Universidade Católica de Minas Gerais, Brasil juliopinto@pucminas.br

Vice-presidente

Itania Maria Mota Gomes

Universidade Federal da Bahia, Brasil

itania@ufba.br

Secretária-Geral

Inês Vitorino

Universidade Federal do Ceará, Brasil

inesvic@gmail.com 